\title{
AS DIVERSAS FACES DO ENEM: ANÁLISE DO PERFIL DOS PARTICIPANTES (1999-2007)
}

ANA PAULA CORTI

\section{RESUMO}

A visibilidade pública do Exame Nacional do Ensino Médio vem aumentando consideravelmente nos últimos anos, sobretudo por meio da mídia escrita e televisiva, que enfatiza um ranqueamento de escolas no país. Essa abordagem acaba por associar o Exame a uma avaliação do ensino médio nacional e, ao mesmo tempo, das escolas individualmente. Este artigo sustenta que, contrariando os discursos governamental e midiático, esse exame, desde sua origem, está longe de uma efetiva avaliação do ensino médio como etapa de ensino, e que essa distância continuou crescendo ao longo dos anos e das mudanças introduzidas no exame. A metodologia adotada no artigo consistiu na análise do perfil dos participantes do exame no período de 1999 a 2007 que revela sua heterogeneização, com o decréscimo acentuado do número de concluintes em relação ao número cada vez maior de egressos.

PALAVRAS-CHAVE ENEM • ENSINO MÉdIO - AVALIAÇÃo EM LARGA ESCALA. 


\section{RESUMEN}

La visibilidad pública del Examen Nacional de Enseñanza Media viene aumentando considerablemente en los últimos años, sobre todo a través de la prensa escrita y la televisión que hacen hincapié en un ranking de las escuelas en el país. Este enfoque acaba asociando el examen a una evaluación de la enseñanza media nacional y, al mismo tiempo, de las escuelas de forma individual. Este artículo sostiene que, contrariamente a los discursos gubernamentales y de los medios de comunicación, este examen, desde su origen, está lejos de una efectiva evaluación de la enseñanza media como una etapa de la enseñanza, y que esta distancia fue creciendo a lo largo de los años y de los cambios introducidos por el examen. La metodología adoptada en el artículo consistió en el análisis del perfil de los participantes del examen en el período de 1999 a 2007 que revela su heterogeneidad, con una disminución acentuada del número de alumnos que están cursando el último año de la enseñanza media y la participación cada vez mayor de egresados.

\section{PALABRAS Clave ENEM - EDUCACIÓN SECUNDARIA • EVALUACIÓN EN GRAN ESCALA.}

\section{ABSTRACT}

The public visibility of the National High School Examination has increased considerably in recent years, particularly through print and television media, which emphasizes a ranking of schools in Brazil. This approach eventually associates the examination to an evaluation of national secondary school teaching, and at the same time, of the schools individually. This article argues that, contrary to government and media discourses, this exam, from the very beginning, has been a far shot from an effective high school evaluation as a stage in the educational process; furthermore this distance has been increasing over the years and the changes introduced in the exam. The methodology adopted in the study consisted in analyzing the profile of the examination participants in the 1999-2007 period. The results reveal their heterogeneity with a sharp decrease in the number of graduates (people who are attending the last year of high school) and an increase in the number of drop-outs.

KEYWORDS ENEM - SECONDARY SCHOOL - LARGE SCALE ASSESSMENT. 
Tantas jaulas, tantos pequenos teatros, em que cada ator está sozinho, perfeitamente individualizado e constantemente visível. [...] É visto, mas não vê; objeto de uma informação, nunca sujeito de uma comunicação.

Michel Foucault, Vigiar e punir, 1987.

No dia 17 de agosto de 2012, foi publicada matéria no portal G1 com o título: "MEC quer integrar currículo e pode usar Enem para avaliar ensino médio". Na sequência lê-se: "Governo pretende reduzir a fragmentação dos conteúdos na sala de aula. Inep vai estudar uso do Enem como 'termômetro' de qualidade da escola" (MORENO, 2012).

Não se trata de uma notícia isolada. Desde sua criação em 1998, o Exame Nacional do Ensino Médio (Enem) vem tendo grande repercussão na mídia, e é interpretado de acordo com múltiplos significados e objetivos. Um desses objetivos seria avaliar a qualidade do ensino médio nacional; outro seria induzir mudanças no currículo dessa etapa.

O discurso governamental e midiático a respeito do Enem variou no tom e na ênfase ao longo desses 15 anos de existência, mas sempre esteve presente uma visão do exame como "retrato" do ensino médio. Neste artigo pretendemos problematizar essa ideia a partir de uma análise do perfil dos participantes ao longo dos anos. 
Os dados foram extraídos de relatórios pedagógicos produzidos pelo Instituto de Estudos e Pesquisas Educacionais Anísio Teixeira (Inep) nos anos de 1999, 2001, 2003, 2005 e 2007. A análise permitirá abarcar o período total de nove anos (1999 a 2007) com base nos dados dos cinco relatórios anuais. Infelizmente, não conseguimos ter acesso aos relatórios de 1998, 2008, 2009 e 2010.

Como pesquisadora do ensino médio no doutorado, fui movida pelo objetivo de compreender de forma mais fundamentada a identidade de um exame que, nos últimos anos, ampliou sua visibilidade pública e canalizou praticamente todos os debates acerca daquela etapa educacional. Para Carneiro (2012),

Em sua versão atual, o Enem produziu o mais arrojado esquema de publicidade em torno de notícias de educação na mídia nacional de todos os tempos. Levantamentos feitos nos principais jornais e revistas do país nos últimos 12 meses (jan. 2010-jan. 2011) indicam que 74\% dos noticiários sobre educação trataram do tema Enem/vestibular. (p. 25)

Presotti (2012) analisa as representações produzidas pela revista Veja sobre o Enem, e constata uma convergência entre o discurso governamental e o discurso midiático:

Ao analisarmos as representações do Enem na revista Veja, de 1998 a 2011, percebemos uma forte associação entre a representação aí tecida e a oficial, exposta nos relatórios pedagógicos e nas normativas do Exame. Entre os fatores correspondentes destacamos a significação do Exame como um indicador de qualidade da educação e sua função de indutor curricular no ensino médio, entendendo-o como qualificado substituto das funções que até então seriam exercidas pelos vestibulares. Esses traços de continuidade tornam-se mais evidentes com a divulgação dos resultados por escola, com mais de 10 alunos participantes, feita pelo Inep a partir dos resultados da edição de 2005. A Publicização dos resultados amplia consideravelmente o número de referências ao Enem na revista, sendo 13 referências, de 1998 a 2005, e 66, de 2006 a 2012. (p. 152) 
A autora também assinala que a revista teve um papel importante na construção de consensos sobre uma noção de qualidade educacional que elege a gestão empresarial como a panaceia para as dificuldades dos sistemas de ensino. Os dados oficiais divulgados pelo MEC e Inep, bem como pelo Fundo das Nações Unidas para a Infância (Unicef) e Organização para a Cooperação e Desenvolvimento Econômico (OCDE), contribuíram na formulação do discurso da revista, servindo como fundamentação empírica de seus argumentos. Presotti (2012) demonstra de forma bastante interessante o quanto a construção midiática do Enem participa de um "jogo de regulação social”.

A forte visibilidade do exame dissemina representações que precisam ser analisadas e problematizadas, tendo em vista a construção de um debate mais democrático das práticas avaliativas do Estado brasileiro. Esperamos que os dados, ainda que limitados em seu recorte e relacionados apenas ao perfil sociodemográfico e escolar dos participantes, possam contribuir na construção de outras interpretações, distintas das hegemônicas.

\section{ENEM: ALGUMAS CONSIDERAÇÕES HISTÓRICAS E CONCEITUAIS}

O Enem foi criado em 1998, na gestão do presidente Fernando Henrique Cardoso, e sob a liderança do ministro da Educação Paulo Renato, num contexto mais amplo da reforma do ensino médio no país, consubstanciada nos seguintes marcos legais:

1. Lei de Diretrizes e Bases da Educação n. 9.394, de 20 de dezembro de 1996.

2. Decreto Federal 2.208 de 1997. Regulamenta a educação profissional e a torna independente do ensino médio, podendo ser oferecida de forma concomitante ou sequencial a ele.

3. Parecer n. 15/1998. Conselho Nacional de Educação. Diretrizes Curriculares Nacionais para o Ensino Médio.

4. Parâmetros Curriculares Nacionais para o Ensino Médio (PCN). 
Não é objetivo deste trabalho discutir a reforma do final dos anos 1990, mas vale ressaltar uma de suas características principais que foi a de buscar um ajustamento conceitual e pedagógico à recente inclusão do ensino médio na educação básica (Lei de Diretrizes e Bases - LDB - de 1996), avançando no projeto de construção de uma escola única de formação geral no país. ${ }^{1}$

Nesse contexto, o Enem passou a ser um elemento importante cujos objetivos foram expressos da seguinte forma em seu documento básico:

O Enem será realizado anualmente, com o objetivo fundamental de avaliar o desempenho do aluno ao término da escolaridade básica, para aferir o desenvolvimento de competências fundamentais ao exercício pleno da cidadania. Pretende, ainda, alcançar os seguintes objetivos específicos: a) oferecer uma referência para que cada cidadão possa proceder a sua autoavaliação com vistas às suas escolhas futuras, tanto em relação ao mercado de trabalho quanto em relação à continuidade de estudos; b) estruturar uma avaliação da educação básica que sirva como modalidade alternativa ou complementar aos processos de seleção nos diferentes setores do mundo do trabalho; c) estruturar uma avaliação da educação básica que sirva como modalidade alternativa ou complementar aos exames de acesso aos cursos profissionalizantes pós-médios e ao ensino superior. (BRASIL, 1998, grifos da autora)

O trecho acima explicita como objetivo geral do Enem a aferição das competências adquiridas pelos estudantes ao término da educação básica, e como objetivos específicos, propiciar a autoavaliação das pessoas acerca de seu processo de escolarização e constituir um processo de seleção alternativo voltado ao mundo do trabalho, às universidades e aos cursos profissionalizantes.

Já em sua concepção inicial, constata-se a baixa relação do Enem com o ensino médio em si, uma vez que se vincula mais a uma ideia de "balanço" de todo o percurso da educação básica. Da mesma forma, a perspectiva de constituir-se como exame de seleção para vagas no mercado de

1 Não desconsideramos que, desde a década de 1950, o país já vinha buscando a superação da dualidade histórica do ensino médio entre formação profissional versus formação propedêutica, como bem aponta Beisiegel (2002). Mas acreditamos que a reforma dos anos 1990 foi um capítulo importante nessa construção, na medida em que, por um lado, preconizou a massificação do ensino médio de formação geral e, por outro, buscou desvinculá-lo do ensino profissional por meio do Decreto n. 2.208 de 1997. 
2 A TRI consiste num modelo matemático que atribui importância a cada item, e não à soma dos acertos. Para cada item é construído um modelo representado por três parâmetros: a discriminação (que ajuda a diferenciar a habilidade dos alunos), o grau de dificuldade e o acerto casual. Cada item é pré-testado e gera um padrão de comportamento de resposta ao item. E por isso se diz que o modelo é "antichute", pois demonstra quando o aluno "chutou" a questão, já que todos os itens possuem uma discriminação de

dificuldade, de forma que se espera que o aluno que acertou os itens dificeis tenha acertado os itens fáceis. Se ele acertou o difícil e errou o fácil, é porque "chutou". O modelo já e adotado no Saeb desde 1995

3 A forma de divulgação dos resultados de uma avaliação é crucial, pois direciona nosso olhar para certos dados, e pode bloquear a visão de outros aspectos. Certamente, a forma como o Inep divulga os resultados do Enem estimula a elaboração de comparações entre as escolas. trabalho e nas instituições educacionais igualmente revela baixo vínculo com o ensino médio. Além disso, desde o início, o exame sempre foi acessível a pessoas sem o ensino médio completo.

Desde a edição do documento básico mencionado anteriormente, passaram-se quinze anos, ao longo dos quais o Enem passou por transformações significativas, tanto em termos das regras orientadoras e objetivos quanto da magnitude e perfil de alunos atraídos para sua realização - fatores que certamente estão inter-relacionados.

As provas do Enem não eram comparáveis, pois não utilizavam uma mesma escala de proficiência, como ocorria, por exemplo, no Sistema Nacional de Avaliação da Educação Básica (Saeb). A partir de 2009, com a mudança na metodologia utilizada e a adoção da Teoria da Resposta ao Item (TRI), ${ }^{2}$ as provas em si passaram a ser comparáveis, muito embora a comparação de seus resultados continue a ser questionável, já que a base de respondentes apresenta uma forte flutuação ano a ano, e, como veremos, apresentou tendência à heterogeneização. Por ser uma avaliação voluntária, não se pode trabalhar com um universo homogêneo e conhecido de respondentes no Enem.

Além disso, é importante ressaltar que o Enem não é uma avaliação de sistema educacional, mas sim um exame individual, voltado àqueles que já concluíram ou estão concluindo o ensino médio. Sousa (2011) argumenta que a reorganização do Enem em 2009 apenas reforçou e ampliou seu desenho inicial como uma avaliação individual dos alunos e ex-alunos, um exame que sugere uma interpretação também individualizada dos resultados, que são tomados como fruto do desempenho individual, omitindo a importância das políticas educacionais e de outros fatores para a construção de tais resultados.

Apesar disso, os usos dos seus resultados pelos meios de comunicação, estimulados pelo governo federal, ${ }^{3}$ vêm difundindo a ideia de que o Enem avalia a qualidade do ensino médio no Brasil e de que tais resultados podem e devem ser usados como forma de controle social das escolas. 
De fato, os usos que se fazem das avaliações de larga escala são atualmente o foco do debate entre muitos autores. Pesquisadores como Freitas (2011), Afonso (2009), Casassus (2009), Andrews (2012), Sousa (2010) e Oliveira (2005) posicionam-se de forma crítica aos usos que têm sido feitos das avaliações de larga escala, embora não se posicionem contrariamente às avaliações em si mesmas, ou à atividade de avaliar de maneira genérica.

Assim, parece ser cada vez mais necessário articular a análise de uma avaliação do ponto de vista intrínseco (técnico, metodológico e conceitual) com sua dimensão extrínseca, qual seja, dos usos e significados sociais construídos em torno dela.

FIGURA 1 - Enem: 1998 a 2010

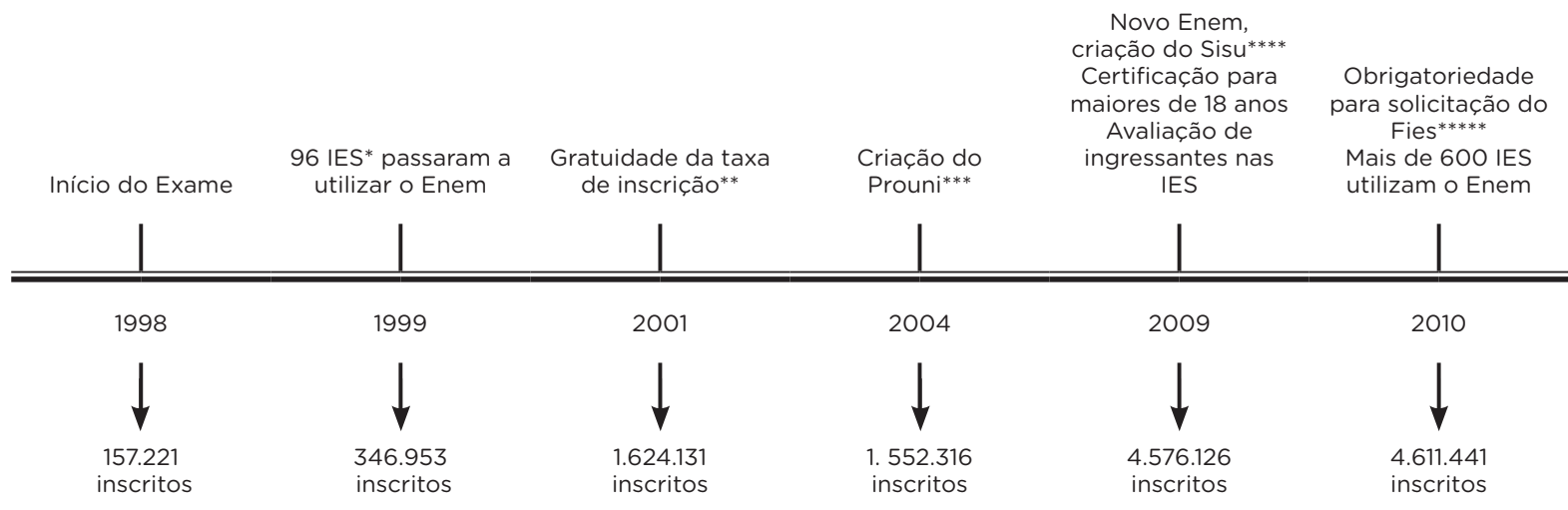

* IES: Instituições de Ensino Superior

**O Ministério da Educação concedeu inscrição gratuita aos concluintes do ensino médio em 2001, aos que concluíram o ensino médio na modalidade Educação de Jovens e Adultos nos doze meses anteriores ao período de inscrição e aos concluintes e egressos do ensino médio em qualquer das modalidades que se declararam impossibilitados de pagar a taxa de inscrição.

*** Prouni: Programa Universidade para Todos

****Sistema de Seleção Unificada. Em 2009 o Enem passou a ser a única forma de disputar vagas em 51 IES.

*****Financiamento ao estudante do Ensino Superior

Fonte: Elaboração da autora.

O diagrama acima indica alguns marcos importantes para a compreensão do histórico do Enem e de sua magnitude. É preciso salientar que, apesar do diagrama trazer dados que vão até o ano de 2010, neste trabalho focalizaremos o período de 1999 a 2007. 


\section{PERFIL SOCIOECONÔMICO E ESCOLAR DOS PARTICIPANTES}

TABELA 1 - Enem, número de inscritos e sua variação percentual em relação ao ano anterior. Brasil, 1998 a 2007

\begin{tabular}{c|c|c}
\hline ANO & NÚMERO DE INSCRITOS & $\begin{array}{c}\text { VARIAC̃ÃO PERCENTUAL EM } \\
\text { RELAÇÃO AO ANO ANTERIOR }\end{array}$ \\
\hline 1998 & 157.221 & \\
\hline 1999 & 346.953 & $+120,0 \%$ \\
\hline 2000 & 390.180 & $+12,5 \%$ \\
\hline 2001 & 1.624 .131 & $+316,0 \%$ \\
\hline 2002 & 1.829 .170 & $+12,5 \%$ \\
\hline 2003 & 1.882 .393 & $+2,9 \%$ \\
\hline 2004 & 1.552 .316 & $-17,5 \%$ \\
\hline 2005 & 3.004 .491 & $+93,6 \%$ \\
\hline 2006 & 3.742 .827 & $+24,5 \%$ \\
\hline 2007 & 3.584 .569 & $-4,5 \%$ \\
\hline
\end{tabular}

Fonte: Elaboração da autora com base em dados do Inep (BRASIL, 1999-2007).

GRÁFICO 1 - Enem, número de inscritos, 1998 a 2007

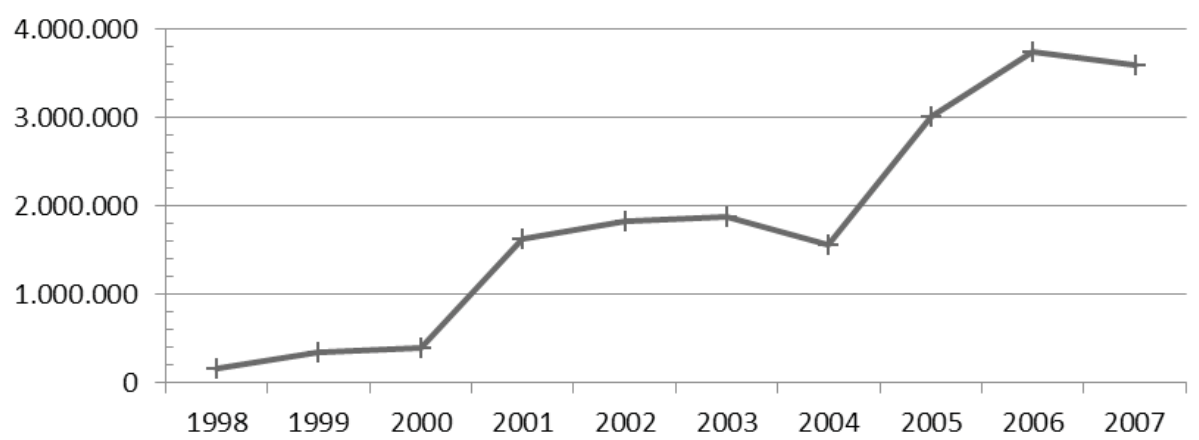

Fonte: Elaboração da autora com base em dados do Inep (BRASIL, 1998-2007).

A primeira edição do exame contou com mais de 150 mil participantes, número que atingiu seu ápice em 2006. Ressalte-se que o ano de 2009 assistiu a um aumento ainda maior em função da reestruturação do Enem e sua articulação ao Sisu (Sistema de Seleção Unificada), mas vamos aqui nos deter apenas no período até 2007. É importante mencionar que o exame apresenta, em geral, uma taxa de absenteísmo de cerca de 30\%; por isso, o universo de inscritos é bem diferente do universo de participantes efetivos. 
Em que pese ao vertiginoso aumento nas inscrições do Enem já desde 1999, podemos considerar que a primeira grande explosão ocorreu em 2001, em função da gratuidade da taxa de inscrição (ver Figura 1). Isso revela que o exame, até esse momento, era muito seleto e focado nos concluintes e egressos de escolas privadas (49\% do total de participantes).

Certamente, o exame modificou-se com essa medida democratizadora, já que 82,6\% dos inscritos em 2001 tiveram isenção da taxa, e o resultado foi uma abrangência sensivelmente maior, alcançando $54 \%$ dos concluintes do ensino médio no país (contra 14,4\% em 2000), com significativas modificações no perfil dos participantes, como veremos mais à frente.

TABELA 2 - Número de participantes do Enem e número dos que responderam ao questionário socioeconômico, Brasil, 1999 a 2007

\begin{tabular}{c|c|c}
\hline ANO & PARTICIPANTES & $\begin{array}{c}\text { QUESTIONÁRIOS } \\
\text { SOCIOECONÔMICOS } \\
\text { VÁLIDOS }\end{array}$ \\
\hline 1999 & 315.960 & 308.514 \\
\hline 2001 & 1.200 .883 & $*$ \\
\hline 2003 & 1.322 .644 & $*$ \\
\hline 2005 & 2.200 .618 & $*$ \\
\hline 2007 & 2.738 .610 & $*$ \\
\hline *Informação não divulgada. & & \\
Fonte: Elaboração da autora com base em dados do Inep (BRASIL, 1999-2007).
\end{tabular}

A Tabela 2 apresenta o universo de pessoas que servirá de referência para nossas análises do perfil socioeconômico dos participantes do Enem. Após 1999, lamentavelmente, os relatórios pedagógicos do Inep omitem a informação sobre a quantidade de questionários socioeconômicos respondidos e válidos, o que nos impede de conhecer o universo objetivo de respondentes aos quais os dados se referem. 
TABELA 3 - Distribuição percentual dos participantes do Enem quanto à conclusão do ensino médio, Brasil, 1999 a 2007

\begin{tabular}{l|c|c|c|c|c}
\hline & 1999 & 2001 & 2003 & 2005 & 2007 \\
\hline Egressos & 35,0 & 30,0 & 22,0 & 44,9 & 54,1 \\
\hline Concluintes & 65,0 & 70,0 & 57,8 & 40,8 & 33,2 \\
\hline \begin{tabular}{l} 
Vão concluir posteriormente \\
\hline Sem resposta
\end{tabular} & - & - & 19,0 & 14,3 & 12,8 \\
\hline \begin{tabular}{l} 
ou inválido \\
\hline
\end{tabular} & - & - & 1,2 & - & - \\
\hline
\end{tabular}

OBS: Em 2003 foi incluído o quesito "ano de conclusão do ensino médio" no questionário socioeconômico, o que possibilitou identificar os alunos que se formariam após o ano de realização do exame, e subtraí-los da categoria "concluintes". Até 2003 os dados dos concluintes agregam os que se formaram no ano do exame, e os que se formariam após o ano do exame. Fonte: Elaboração da autora com base em dados do Inep (BRASIL, 1999-2007).

O público potencial do Enem é aquele que concluiu o ensino médio em anos anteriores à realização do exame, ou que está concluindo no ano do exame. Essas categorias de participantes costumam ser classificadas como: egressos (concluíram o ensino médio em anos anteriores à realização do Exame) e concluintes (estão concluindo o ensino médio no ano de realização do Exame).

Vemos na tabela acima que o percentual de concluintes sobre o universo total de participantes teve um crescimento até 2001, e a partir de 2003 começou a declinar, antes mesmo do Prouni (Programa Universidade para Todos). Com a criação do programa e sua vinculação obrigatória ao Enem a partir de 2004, isso será acentuado e irá gerar um aumento de $96 \%$ nas inscrições de 2004 para 2005, já que o exame passou a ser mais procurado por pessoas interessadas em disputar uma bolsa em universidades privadas, por pessoas já formadas e com idades mais elevadas. Com isso, há uma heterogeneização do público participante.

A gratuidade da taxa de inscrição instituída em 2001, como forma de atrair maior quantidade de concluintes do ensino médio, conseguiu efetivamente cumprir esse objetivo, mas com base na diversificação de objetivos abarcados pelo exame a partir de 2004, voltando-se cada vez mais para o ingresso no ensino superior, esse êxito em 
aumentar o número de concluintes foi se perdendo e se diluindo.

A meu ver, os percentuais corroboram a percepção de que o Enem é um exame que já nasceu distanciado do ensino médio, e vem se distanciando cada vez mais ao longo dos últimos anos, revelando-se um instrumento muito limitado para avaliar as propriedades ou as qualidades daquela etapa de ensino.

Supondo que dentre os egressos do ensino médio (os não concluintes) exista uma variedade e heterogeneidade de perfis, considerando a faixa etária, o ano em que concluíram o ensino médio, os objetivos perseguidos ao fazer a prova, o nível de proximidade ou distanciamento em relação à vida escolar, o tipo de inserção social, pode-se dizer que os resultados de mais da metade dos participantes do Enem não são sequer comparáveis com os resultados da outra metade.

TABELA 4 - Distribuição percentual dos participantes do Enem por tipo de escola de ensino médio cursada

\begin{tabular}{l|r|r|r|r|c}
\hline TIPO DE ESCOLA & 1999 & 2001 & 2003 & 2005 & 2007 \\
\hline Pública & 43,0 & 66,0 & 70,4 & 81,1 & 83,3 \\
\hline Pública e privada & 8,0 & 15,0 & 6,5 & 5,0 & 4,7 \\
\hline Privada & 49,0 & 19,0 & 22,2 & 13,8 & 11,8 \\
\hline
\end{tabular}

Fonte: Elaboração da autora com base em dados do Inep (BRASIL, 1999-2007).

Nos primeiros anos de implementação do Enem, os participantes eram, em grande parte, provenientes de escolas privadas. A partir de 2001, isso sofre uma inflexão e os alunos de escolas públicas vão se tornando progressivamente maioria no exame, atingindo um percentual de $83 \%$ em 2007. Isso revela que: 1) o exame tornou-se mais acessível em função da possibilidade de gratuidade da taxa de inscrição; 2) os alunos das redes públicas passaram a procurar mais o exame em função dos programas de inclusão social no ensino superior privado (e posteriormente, em 2009, em menor magnitude, em função da busca por vagas em institutos e universidades federais). 
TABELA 5 - Distribuição percentual dos participantes do Enem por turno em que foi cursado o ensino médio

\begin{tabular}{l|c|c|c|c|c|c}
\hline TURNO & 1999 & 2001 & 2003 & 2005 & 2007 \\
\hline Diurno & 72 & 53 & 53,6 & 49,0 & 48,8 \\
\hline Noturno & 16 & 31 & 25,1 & 28,6 & 28,3 \\
\hline Ambos & 12 & 12 & 20,1 & 22,4 & 22,8 \\
\hline
\end{tabular}

Fonte: Elaboração da autora com base em dados do Inep (BRASIL, 1999-2007).

O ensino médio brasileiro expandiu suas matrículas, em boa parte, com a criação de cursos noturnos a partir dos anos 1980 e 1990. Em 1999, 54,5\% das matrículas no ensino médio regular do país eram no período noturno. No entanto, apenas 16\% dos participantes do Enem nesse ano haviam estudado nesse período. De uma maneira geral, vem se configurando uma tendência à diminuição das matrículas noturnas no ensino médio em âmbito nacional.

A democratização do exame, com a inclusão crescente de alunos das redes públicas, permitiu aumentar o percentual de participantes concluintes ou egressos de cursos noturnos, mas, talvez, os dados possam ser vistos sob um prisma complementar: a diversificação do público do Enem com base no Prouni atraiu pessoas formadas em anos anteriores, em que havia maior chance de elas terem se formado em cursos noturnos.

É plausível afirmar que os alunos que estudam ou estudaram à noite procuram proporcionalmente menos o Enem, quando comparados com aqueles que estudaram no período diurno, o que sugere menor chance de ingresso no ensino superior. Mas, apesar dessa sub-representação do período noturno, não deixa de ser significativo o aumento no número de inscrições de alunos que frequentaram o ensino médio noturno. 
TABELA 6 - Distribuição percentual dos participantes do Enem por faixa etária

\begin{tabular}{l|cc|c|c|c|c}
\hline FAIXA ETÁRIA & 1999 & 2001 & 2003 & 2005 & 2007 \\
\hline Até 18 & & 194,7 & 50,6 & 58,1 & 44,3 & 38,9 \\
\hline $19-20$ & 21,5 & 25,0 & 19,9 & 19,9 & 18,7 \\
\hline $21-22$ & 5 & 5,9 & 9,5 & 8,1 & 10,2 & 11,1 \\
\hline $23-26$ & 3,6 & 7,3 & 6,2 & 11,5 & 13,1 \\
\hline Mais de 26 & & 4,0 & 7,5 & 7,1 & 14,2 & 18,1 \\
\hline
\end{tabular}

Fonte: Elaboração da autora com base em dados do Inep (BRASIL, 1999-2007).

Coerentemente com os dados já analisados, notamos a diversificação do perfil etário dos participantes do Enem ao longo do tempo: mais de 60\% deles tinham até 18 anos em 1999; e, apesar da diminuição progressiva da distorção idade-série no ensino médio, em níveis nacionais, que vem causando uma juvenilização do público do ensino médio, notamos um "envelhecimento" dos participantes do Enem.

Houve aumento de $14 \%$ na participação daqueles com mais de 26 anos de idade, de $10 \%$ dos que têm entre 23 e 26 anos e de $5 \%$ entre os que têm entre 21 e 22 anos.

Ganha reforço a explicação acerca da diversificação do público que procura o exame e a tendência à sua apropriação como instrumento de acesso ao ensino superior.

TABELA 7 - Distribuição percentual dos participantes do Enem por sexo

\begin{tabular}{l|cc|c|c|c|c}
\hline SEXO & 1999 & 2001 & 2003 & 2005 & 2007 \\
\hline Masculino & 39,9 & 37,1 & 39,4 & 37,3 & 37,5 \\
\hline Feminino & 60,1 & 62,9 & 60,3 & 62,7 & 62,5 \\
\hline
\end{tabular}

Fonte: Elaboração da autora com base em dados do Inep (BRASIL, 1999-2007).

É sabido que o número de matrículas das moças no ensino médio vem há muitos anos superando o dos rapazes: em 1999 elas eram $54,6 \%$ contra $44,9 \%$, e em $2007,54,7 \%$ contra $45,3 \%$. Isso se reflete na distribuição dos participantes do Enem por sexo, de forma ainda mais acentuada, já que elas representam cerca de $60 \%$ das pessoas que fazem a prova, mantendo 
essa posição ao longo dos anos. As mulheres vêm apresentando melhores indicadores educacionais em muitos quesitos: maior número médio de anos de estudo, menores taxas de reprovação e de evasão e maior nível de conclusão no ensino médio. Este último aspecto pode estar diretamente ligado à maior atratividade das mulheres para o Enem.

TABELA 8 - Distribuição percentual dos participantes do Enem por raça/cor

\begin{tabular}{l|c|c|c|c|c|c}
\hline RAÇA/COR & 1999 & 2001 & 2003 & 2005 & 2007 \\
\hline Branco & 76,5 & 58,5 & 51,2 & 45,6 & 43,7 \\
\hline Negro & 1,9 & 5,3 & 7,3 & 11,9 & 12,3 \\
\hline Pardo/mulato & $\vdots$ & 16,4 & 30,5 & 34,1 & 38,3 & 39,7 \\
\hline Indígena & 0,5 & 0,5 & 0,9 & 0,9 & 0,9 & 0,8 \\
\hline Amarelo & & 4,0 & 4,8 & 5,1 & 3,4 & 3,3 \\
\hline Sem informação & $\vdots$ & 1,2 & - & - & - & - \\
\hline
\end{tabular}

Fonte: Elaboração da autora com base em dados do Inep (BRASIL, 1999-2007).

No que tange ao quesito cor/raça evidencia-se um aumento dos participantes negros e pardos/mulatos ao longo dos anos. Os negros aumentaram sua participação em 10\%, e os pardos/mulatos, em $23,3 \%$, ao longo dos nove anos analisados, o que significa dizer que em 2007 os negros/pardos/ mulatos já são mais da metade dos participantes do exame (52\%). Entre 1999 e 2007, houve um aumento de 33\% na presença de negros/pardos/mulatos na avaliação.

Tendo em vista a existência de fortes desigualdades raciais no Brasil e seus reflexos no processo de escolarização das crianças e dos jovens, chega a causar certa surpresa a presença tão significativa dos negros. Isso sugere uma forte relação com as políticas de ação afirmativa no ensino superior, que vêm sendo adotadas a partir de 2001, tendo como uma das principais medidas as cotas raciais.

Em levantamento realizado por Heringer e Ferreira (2009), foram identificadas 79 IES no Brasil que promovem algum tipo de ação afirmativa. O Prouni também teve papel fundamental para a inclusão da população negra na universidade 
privada, baseada em incentivos fiscais. Como se sabe, o Enem teve e continua a ter um papel central nesse processo, como requisito obrigatório para pleitear as bolsas do Prouni, e como seleção (parcial ou integral) para muitas universidades públicas. Esses dados reiteram a aproximação crescente do Enem com o objetivo de selecionar para o ensino superior, antes mesmo da reorganização do Exame em 2009.

TABELA 9 - Distribuição percentual dos participantes do Enem por situação em relação ao trabalho

\begin{tabular}{l|c|c|c|c|c}
\hline $\begin{array}{l}\text { SITUAČÃO EM RELAÇÃO } \\
\text { AO TRABALHO }\end{array}$ & 1999 & 2001 & 2003 & 2005 & 2007 \\
\hline Trabalham & 38,9 & 51,8 & 47,1 & 58,6 & 61,6 \\
\hline Nunca trabalharam & 46,7 & 30,2 & 30,2 & 22,8 & 21,2 \\
\hline $\begin{array}{l}\text { Nunca trabalharam, mas estão } \\
\text { procurando emprego }\end{array}$ & 13,2 & 18,0 & 19,9 & 18,6 & 17,2 \\
\hline \begin{tabular}{l} 
Sem resposta ou inválido \\
\hline
\end{tabular} & - & - & 2,8 & - & - \\
\hline
\end{tabular}

Fonte: Elaboração da autora com base em dados do Inep (BRASIL, 1999-2007).

Um dos traços distintivos do ensino médio brasileiro em relação aos demais países, inclusive nossos vizinhos sul-americanos, é a concomitância entre estudo e trabalho para aqueles que frequentam esta etapa educacional. É bem verdade que essa realidade parece estar se alterando com as políticas de correção de fluxo, que vêm produzindo um rejuvenescimento dos alunos do ensino médio, com a redução da distorção idade-série, que sempre foi alta nesta etapa de ensino.

Se, na tendência nacional, os alunos do ensino médio estão cada vez mais novos em razão da diminuição progressiva da distorção idade-série, cuja taxa foi de 34,4\% em 2009 (65,6\% dos alunos do país estão em idade correta), e se isso vem acarretando um deslocamento na questão da educação e trabalho nesta etapa, com a diminuição de alunos que trabalham ao cursar o ensino médio, por que vem ocorrendo o contrário com os participantes do Enem?

Notamos que o percentual de alunos que haviam conciliado trabalho e estudo no ensino médio, ou estavam conciliando, atingiu $61,6 \%$ em 2007. Se somarmos com 
aqueles que declararam estar procurando emprego, temos um total de $78,8 \%$ de respondentes para os quais a questão do trabalho está presente.

As tendências encontradas no perfil dos participantes do Enem, no que tange à condição trabalhadora da grande maioria, indicam os riscos de utilizar tais dados para análise do perfil sociodemográfico no ensino médio do país, pois elas parecem caminhar em direções contrárias.

Os dados da Tabela 9 podem ser vistos também como um indicador da tendência que a democratização do ensino superior está gerando no sentido da inclusão de estudantes-trabalhadores nos sistemas, o que revela desafios para a permanência e progressão desses alunos, tendo em vista as exigências de um curso universitário e os desafios de conciliá-lo com o trabalho. Corrobora a necessidade de analisar mais detidamente os impactos e desdobramento dessas mudanças no sistema de ensino superior brasileiro.

TABELA 10 - Distribuição percentual dos participantes do Enem por renda familiar em número de salários mínimos

\begin{tabular}{l|c|c|c|c|c}
\hline RENDA FAMILIAR & 1999 & 2001 & 2003 & 2005 & 2007 \\
\hline Até 1 & 1,2 & 6,3 & 9,6 & 13,5 & 15,5 \\
\hline 1 a 2 & 4,9 & 20,5 & 24,2 & 33,6 & 36,4 \\
\hline 2 a 5 & 17,7 & 33,1 & 33,8 & 34,7 & 33,1 \\
\hline 5 a 10 & 27,6 & 20,5 & 16,4 & 10,8 & 8,4 \\
\hline 10 a 30 & 31,7 & 14,0 & 10,2 & 4,7 & 3,9 \\
\hline 30 a 50 & 8,7 & 2,9 & 1,9 & 0,8 & 0,5 \\
\hline Mais de 50 & 6,5 & 1,6 & 1,0 & 0,4 & 0,3 \\
\hline Sem renda & 0,6 & 1,2 & 1,5 & 1,4 & 1,6 \\
\hline Sem informação & 1,1 & - & 1,5 & - & - \\
\hline
\end{tabular}

Fonte: Elaboração da autora com base em dados do Inep (BRASIL, 1999-2007).

Na tabela acima, aparece com bastante nitidez um processo de atração crescente do Enem em relação às pessoas de baixa renda. Novamente, o marco divisor parece ter sido o ano de 2001, mas, após o Prouni, essa tendência ganhou novo reforço, consubstanciando um cenário em que 85\% dos 
participantes do exame em 2007 tinham renda familiar de até cinco salários mínimos, quando em 2001 esse percentual era de $59,9 \%$, e em 1999 , de $23,8 \%$.

TABELA 11 - Distribuição percentual dos participantes do Enem por escolaridade do pai e da mãe

\begin{tabular}{|c|c|c|c|c|c|c|c|c|c|c|}
\hline \multirow{2}{*}{ ESCOLARIDADE } & \multicolumn{2}{|c|}{1999} & \multicolumn{2}{|c|}{2001} & \multicolumn{2}{|c|}{2003} & \multicolumn{2}{|c|}{2005} & \multicolumn{2}{|c|}{2007} \\
\hline & Pai & Mãe & Pai & Mãe & Pai & Mãe & Pai & Mãe & Pai & Mãe \\
\hline 1a a 4⿳亠口了 série & 20,8 & 18,9 & 31,2 & 30,6 & 29,7 & 28,6 & 34,7 & 32,6 & 34,8 & 32,5 \\
\hline 5a a 8ª série & 11,0 & 12,3 & 15,6 & 18,3 & 15,4 & 17,8 & 16,1 & 18,1 & 16,1 & 18,1 \\
\hline Ensino médio incompleto & 5,8 & 6,5 & 6,6 & 6,7 & 5,8 & 6,6 & 5,6 & 6,5 & 5,4 & 6,3 \\
\hline Ensino médio completo & 17,3 & 22,3 & 16,0 & 18,3 & 16,4 & 19,4 & 16,2 & 19,6 & 16,6 & 20,1 \\
\hline Superior incompleto & 6,9 & 6,6 & 4,0 & 4,1 & 4,0 & 4,3 & 3,0 & 3,1 & 2,7 & 3,0 \\
\hline Superior completo & 24,5 & 22,8 & 10,9 & 10,9 & 10,3 & 10,7 & 6,7 & 7,8 & 5,8 & 7,1 \\
\hline Pós-graduação & 7,7 & 6,4 & 2,9 & 3,0 & 3.2 & 3,6 & 1,9 & 2,6 & 1,8 & 2,8 \\
\hline Não tem & 2,6 & 2,7 & 7,2 & 6,4 & 7,0 & 5,9 & 8,6 & 7,5 & 8,9 & 7,7 \\
\hline Sem resposta ou inválido & - & - & - & - & 1,1 & 3,2 & 7,2 & 2,2 & 7,4 & 2,1 \\
\hline
\end{tabular}

Fonte: Elaboração da autora com base em dados do Inep (BRASIL, 1999-2007).

A escolaridade do pai e da mãe é considerada um dado importante na análise do perfil socioeconômico em função da forte relação, no nosso país, entre pobreza e exclusão escolar.

Considerando os dados de 2007, vemos que 56\% dos participantes do Enem já possuem ou estão prestes a obter um grau de escolaridade maior do que dos pais: o ensino médio completo.

Ao longo dos anos, nota-se uma diminuição nos níveis de escolaridade do pai e da mãe dos participantes, indicando a composição social mais heterogênea da avaliação e a inclusão de pessoas provenientes de famílias mais pobres.

\section{BREVE BALANÇO E ALGUMAS INDAGAÇÕES}

Os dados analisados permitem tecer algumas observações sobre o perfil dos participantes. 
Foram identificados dois momentos significativos de explosão na procura ao Enem e de heterogeneização de seu público: 2001, com a gratuidade da taxa de inscrição - em termos relativos foi o ano de maior aumento na procura pela prova (+316\%) - e 2005, um ano depois da criação do Prouni, que registrou um aumento de $96 \%$ na procura ao exame.

Assim, embora boa parte de nossa análise seja convergente com a realizada por Freitas, Garcia e Birenbaum (2009), ao analisarem o perfil dos participantes nos anos de 1998, 2001 e 2005, o estudo feito pelos autores não mencionou um aspecto central para a diversificação do perfil do participantes do Enem ao longo do período, que foi a gratuidade da taxa de inscrição do exame instituída em 2001. Os autores atribuem à criação do Prouni a mudança no perfil dos participantes do Enem no período entre 1998 e 2005.

A leitura dos relatórios pedagógicos do exame deixa claro que, já em 2001, o principal objetivo que levava as pessoas a prestarem o exame era a intenção de utilizá-lo como forma de acesso ao ensino superior, o que foi afirmado por mais da metade dos respondentes. Isso revela que, já no quarto ano de realização do exame, sua aproximação com o objetivo de selecionar para o ensino superior já estava bastante configurada.

Costuma-se atribuir ao Prouni toda a responsabilidade pela aproximação do Enem com o ingresso no ensino superior e, posteriormente, ao novo Enem, em 2009, a consolidação dessa tendência com a criação do Sisu. Mas o que os dados apontam é que a vinculação do Enem às perspectivas de ingresso nas universidades, como política pública nacional, já estava claramente delineada na sua origem, e vinha sendo exitosa desde o ano de 2001.

Vamos agora nos concentrar na análise do exame tendo em vista a tendência, já identificada nas tabelas acima, de uma heterogeneização crescente do público participante do Enem a partir de 2001. Acredito ter sido possível identificar o distanciamento do Enem em relação ao ensino médio ao longo dos anos. Mas, surpreendentemente, foi possível perceber que essa distância ja poderia ser vista no próprio documento fundador do Enem, pois nele não encontramos 
nenhuma menção à relação com as políticas de ensino médio, tampouco com o currículo.

Isso leva a considerar que, desde a criação do Exame, ele aparece distanciado de uma perspectiva orientadora das políticas públicas para o ensino médio, situação que vai sendo acentuada ao longo dos anos com base nas medidas governamentais que o direcionam cada vez mais como instrumento de acesso ao ensino superior. ${ }^{4}$

Em estudo em que analisa a pertinência de se considerar o Enem uma política pública, Alves (2009, p. 55) diz: "Podemos afirmar que durante o período de aplicação do Enem, embora tivessem promessas de melhoria do ensino público, nada ocorreu, nenhuma política pública foi incrementada neste sentido".

É preciso que se diga aqui que esta característica não pode ser atribuída às iniciativas do governo Lula junto ao Enem, que caracterizaram o aprofundamento de um modelo que já vinha sendo implementado desde 2001. Isso não significa que as iniciativas do governo Lula (Prouni, Sisu e reformulação do Fies) não tenham tido peso significativo na democratização efetiva das oportunidades de acesso ao ensino superior. Ocorre que tais medidas devem ser tratadas como políticas de democratização do acesso ao ensino superior, e não devem ser confundidas com uma política voltada ao ensino médio. ${ }^{5}$

Mas, se fica evidente o distanciamento do Enem em relação ao ensino médio desde as próprias intenções anunciadas até o perfil de pessoas que ele atrai, por que vem sendo tão difundida pelo governo, na sua forma de divulgação dos resultados, e pela mídia, a ideia de que o Enem permite analisar a qualidade do ensino médio e das escolas?

Os próprios relatórios pedagógicos do Inep afirmam que uma das dimensões da avaliação seria promover "o controle social da escola, pois, com base em seus resultados, o jovem passa a cobrar um melhor desempenho da mesma" (BRASIL, 2007).

Essa é a questão central a ser problematizada, pois fica claro que o Enem é um exame cada vez menos coerente com os usos que temos feito dele, dado que seu desenho técnico e
4 Uma posição diferente é apresentada por Santos ao afirmar que: "O Enem, então, desde sua concepção, objetivava ser o instrumento que forjaria mudanças curriculares significativas no ensino médio" (SANTOS, 2011, p. 200). O autor argumenta que o Exame foi um mecanismo voltado, sobretudo, à reforma curricular do ensino médio, por meio da indução de mudanças nas formas de ingresso ao ensino superior.

5 Jesse Pereira, em sua tese de 2004 sobre o potencial do Enem como elemento de democratização do Ensino Superior para egressos das escolas públicas, constatou que, naquele momento, o Exame gerava um ganho inexpressivo na pontuação final dos alunos egressos de escolas públicas, nos vestibulares da USP, Unesp e Unicamp. O impacto do Enem foi considerado mínimo, e constatou-se que altos desempenhos no Enem estavam muito associados a altos desempenhos dos alunos nos vestibulares daquelas instituições. Em entrevista feita pelo autor com pesquisadores do Núcleo de Apoio ao Estudo de Graduação da USP (Naeg-USP) eles assumiam que qualquer que fosse o peso dado ao Enem no vestibular, não mais do que $5 \%$ dos inscritos sofreriam efeitos na classificação final. 
metodológico não permite a avaliação e o ranqueamento de escolas, e igualmente não consiste num instrumento confiável para avaliar a qualidade do ensino médio brasileiro.

Enquanto se constata um vazio na responsabilidade pública do Estado diante dos resultados do Enem, confirma-se a tendência indicada por Sousa já em 1999: o estímulo à competitividade entre as escolas, a individualização dos resultados educacionais, alimentando a crença liberal no mérito do indivíduo como algo desvinculado dos fatores sociais e econômicos, a introdução de mecanismos de mercado na gestão educacional. A autora aponta que $o$ Enem apenas confirmaria a desigualdade educacional existente no país, e indaga: "Quem se beneficiaria com esta iniciativa?” (SOUSA, 1999, p. 59).

Gostaria de discutir mais detidamente dois problemas que podemos identificar na defesa muitas vezes feita do controle social das escolas por meio do Enem:

1. Essa ideia contraria uma ressalva que pode ser encontrada no mesmo relatório de onde foi extraído o trecho acima, de que os resultados da avaliação só são válidos para o universo de participantes do exame e não podem ser expandidos para uma realidade maior, ou para o ensino médio como um todo. Mas, se os resultados não podem ser expandidos, eles não refletem as características das escolas nas quais os participantes estudaram, ou seja, as escolas não podem ser avaliadas pelos resultados de alguns de seus alunos que fizeram o Enem.

2. Depois de realizar o Enem o aluno não retorna mais à escola de ensino médio, pois já se formou ou está se formando. Sendo assim, como ele poderia realizar alguma cobrança acerca da qualidade da mesma? Como afirma Sousa (1999, p. 58), “o que poderá ser feito retroativamente? Diante da constatação de dadas incompetências, o que poderá um aluno egresso da escola pública fazer? Exigir do poder público um processo de ensino que garanta seu direito à escolarização?".

O processo de responsabilização das escolas já vem sendo feito, indiretamente, mesmo que elas não sofram punições 
pelos sistemas públicos. A publicidade das médias obtidas pelos alunos sugere, de forma tácita, a responsabilidade das escolas por tais resultados. Se isso tem sido positivo para um pequeno grupo seleto de escolas de elite que vem ganhando grande visibilidade pública como baluartes da qualidade de ensino, certamente a maioria das escolas públicas não parece estar se beneficiando com essa suposta estratégia de controle social. A meu ver, a exposição pública não vem colaborando para que escolas com dificuldades possam ser apoiadas e reestruturadas para oferecer uma educação de melhor qualidade.

A forma de nomear as coisas revela modos de representá-las, e me parece que, após 14 anos de existência, já é tempo de questionar a representação falseada do Enem como um exame voltado ao ensino médio. Nesse sentido, talvez se devesse ir exatamente na direção contrária à anunciada pelo atual Ministro da Educação, Aloísio Mercadante: concentrar-se no Saeb, e não no Enem, para construir o debate sobre a qualidade do ensino médio. Como afirmou Sousa em artigo recente:

[...] o Saeb reúne características que permitem reconhecê-lo como um sistema de avaliação de desempenho de alunos do ensino médio. Não se ignoram os seus limites ao circunscrever a noção de qualidade à proficiência dos alunos em determinadas disciplinas escolares, nem os desserviços para a democratização do ensino, que podem ser gerados dependendo do uso que se fizer de seus resultados; no entanto, se aceita que seus resultados expressam uma das facetas de qualidade do ensino médio. O mesmo não se pode afirmar em relação ao Enem, embora este venha sendo difundido como uma avaliação do ensino médio. (SOUSA, 2011, p. 101)

No entanto, talvez seja incoerente com a lógica política abrir mão da visibilidade tão ampla do Enem, ainda que tal visibilidade promova uma distorção do real. Nesse sentido, como diz Foucault, “a visibilidade é uma armadilha” (1987, p. 177). 


\section{REFERÊNCIAS}

AFONSO, A. J. Avaliação educacional: regulação e emancipação. Para uma sociologia das políticas avaliativas contemporâneas. 4. ed. São Paulo: Cortez, 2009.

ALVES, P. A. C. Enem como política pública de avaliação. Dissertação (Mestrado) - Faculdade de Educação, Universidade do Estado do Rio de Janeiro, Rio de Janeiro, 2009.

ANDREWS, C.; VRIES, M. S. de. Pobreza, municipalização e desempenho escolar no Brasil: análise dos resultados do Ideb (2005-2009). Cadernos de Pesquisa, São Paulo, v. 42, n. 147, p. 828-849, set./dez. 2012.

BEISIEGEL, C. de R. O Ensino médio sob a perspectiva da educação básica. In: ZIBAS, Dagmar; AGUIAR, Márcia Ângela da S.; BUENO, Maria Sylvia Simões. 0 ensino médio e a reforma da educação básica. Brasília: Plano, 2002.

BRASIL. Ministério da Educação. Instituto Nacional de Estudos e Pesquisas Educacionais Anísio Teixeira. Enem: Documento Básico. Brasília: MEC/Inep, 1998.

. Enem: Relatório Pedagógico 1999. Brasília: MEC/Inep, 1999.

Enem: Relatório Pedagógico 2001. Brasília: MEC/Inep, 2001.

Enem: Relatório Pedagógico 2003. Brasília: MEC/Inep, 2003.

Enem: Relatório Pedagógico 2005. Brasília: MEC/Inep, 2005.

Enem: Relatório Pedagógico 2007. Brasília: MEC/Inep, 2007.

CARNEIRO, Moaci Alves. 0 nó do ensino médio. Petrópolis: Vozes, 2012.

CASASSUS, Juan. Uma nota crítica sobre a avaliação estandardizada: a perda de qualidade e a segmentação social. Sísifo: Revista de Ciências da Educação, n. 9, p. 71-78, mai./ago. 2009.

FOUCAULT, M. Vigiar e punir. 5 ed. Petrópolis: Vozes, 1987.

FREITAS, Á. H.; FREITAS, E.; GARCIA, V. C.; BIRENBAUM, R. Enem: um demonstrativo das mudanças socioeconômicas no perfil dos participantes. Meta: Avaliação, Rio de Janeiro, v. 1, n. 1, p. 104-124, jan./abr. 2009.

FREITAS, L. C. de. Responsabilização, meritrocacia e privatização: conseguiremos escapar ao neotecnicismo? In: SEMINÁRIO DE EDUCAÇÃO BRASILEIRA DO CEDES, 3., fev. 2011, Campinas. Anais... Campinas: CEDES, 2011.

HERINGER, R.; FERREIRA, R. Análise das principais políticas de inclusão de estudantes negros no ensino superior no Brasil no período 2001-2008. In: HERINGER, R.; PAULA, M. (Org.). Caminhos convergentes. Estado e sociedade na superação das desigualdades raciais no Brasil. Rio de Janeiro: Fundação Heinrich Boll, ActionAid, 2009.

LOPES, A. C.; LÒPEZ, S. B. A performatividade nas políticas de currículo: o caso do Enem. Educação em Revista, Belo Horizonte, v. 26, n. 1, p. 89-110, abr. 2010.

MORAES, C. S. V.; ALAVARSE, O. M. Ensino médio: possibilidades de avaliação. Educação e Sociedade, Campinas, v. 32, n. 116, p. 605-610, jul./set. 2011. 
MORENO, A. C. MEC quer integrar currículo e pode usar Enem para avaliar ensino médio. Portal G1. 17 ago. 2012. Disponível em: <http://g1.globo.com/ vestibular-e-educacao/noticia/2012/08/mec-quer-integrar-curriculo-e-pode-usar-enem-para-avaliar-ensino-medio.html>. Acesso em: 2 dez. 2012.

OLIVEIRA, R. P. de; A.RAÚJO, G. C. de. Qualidade do ensino: uma nova dimensão da luta pelo direito à educação. Revista Brasileira de Educação, São Paulo, n. 28, p. 5-23, jan./abr. 2005.

PEREIRA, J. F. O Enem como como elemento democratizador do acesso ao ensino superior público pelos alunos oriundos das camadas populares. 2004. 230 p. Tese (Doutorado em Educação) - Pontifícia Universidade Católica de São Paulo, São Paulo, 2004.

PRESOTTI, K. Representações do Exame Nacional do Ensino Médio na revista Veja (1998-2011). 2012. 186 p. Dissertação (Mestrado) - Universidade Federal do Espírito Santo, Vitória, 2012.

SANTOS, J. M. C. T. Exame Nacional do Ensino Médio: entre a regulação da qualidade do ensino médio e o vestibular. Educar em Revista, Curitiba, Editora UFPR, n. 40, p. 195-205, abr./jun. 2011.

SOUSA, S. Z. L. de. A que veio o Enem? Revista de Educação AEC, O lugar do ensino médio na educação básica, Brasília, ano 28, n. 113, p. 53-60, 1999.

. Ensino médio: perspectivas de avaliação. Retratos da Escola, Brasília, v. 5, n. 8, p. 99-110, jan./jun. 2011. Disponível em: <http//www.esforce.org. br>. Acesso em: 2 dez. 2012.

SOUSA, S. Z. L. de.; OLIVEIRA, R. P. de. Sistemas estaduais de avaliação: uso dos resultados, implicações e tendências. Cadernos de Pesquisa, São Paulo, v. 40, n. 141, p. 793-822, set./dez. 2010.

\section{ANA PAULA CORTI}

Doutoranda na Faculdade de Educação da Universidade de São Paulo (FE/USP) e docente do Instituto Federal de Educação, Ciência e Tecnologia de São Paulo (IFSP) anapaulacorti@gmail.com 